\title{
REFLEXÕES ACERCA DO MÉTODO DE ANÁLISE DE PERFORMANCE DE FUNDOS DE PREVIDÊNCIA PRIVADA COMPLEMENTAR ABERTA
}

\author{
Eder Antônio Porto ${ }^{1}$
}

RESUMO: O presente artigo tem por objetivo abordar os aspectos mais gerais acerca do método de análise de performance de fundos de investimento em previdência complementar aberta no Brasil e suas potencialidades. Inicialmente, foram abordados tanto a estrutura Regime Geral de Previdência Social (RGPS) quanto do Sistema Financeiro Nacional (SFN) e as distinções entre as entidades de previdência privada de tipo fechado (EFPC) e aberto (EAPC). Ato seguinte, tratamos sobre os aspectos teórico-práticos da análise de performance de fundos de previdência complementar aberta. Considerando a estreita relação entre a finalidade da administração dos recursos financeiros de terceiros e a finalidade social objetiva de fundos de previdência privada complementar aberta, o método de análise da performance de carteiras de fundos de previdência complementar aberta poderia ser entendido como uma espécie de instrumento estatístico que possibilitaria a avaliação de impacto dos reflexos diretos e indiretos tanto para o mercado financeiro quanto para o objetivo social a que se destina?

Palavras-chave: Previdência Social. Entidade Aberta de Previdência Complementar (EAPC). Análise de Performance.

ABSTRACT: This article aims to address the more general aspects of the performance analysis method of open private pension investment funds in Brazil and their potential. Initially, both the General Social Security Regime (RGPS) and the National Financial System (SFN) structure and the distinctions between closed (EFPC) and open (EAPC) private pension entities were addressed. Next, we deal with the theoretical and practical aspects of the performance analysis of open private pension funds. Considering the close relationship between the purpose of managing third party financial resources and the objective social purpose of open private pension funds, the method of analyzing the performance of open private pension fund portfolios could be understood as a kind of statistical instrument that would make it possible to assess the impact of direct and indirect impacts on both the financial market and the social objective for which it is intended?

Keywords: Social Security. Open Supplementary Pension Entity. Performance Analysis.

\footnotetext{
${ }^{1}$ Professor do Curso de Formação de Corretores de Seguro da Escola Nacional de Seguros (ENS). Economista formado pela Pontifícia Universidade Católica de Minas Gerais (PUC-MG). Especialista em Estatística pela Universidade Federal de Minas Gerais (UFMG), ênfase em Análise de Performance de Fundos de Previdência Complementar Aberta. Sócio proprietário na REDEMG Corretora de Seguros Ltda, corretor de seguros todos os ramos (SUSEP 201007324), trabalhou em Minas Brasil e Zurich Seguros. E-mail: ederantonioporto@gmail.com
} 


\section{INTRODUÇÃO}

O presente artigo tem por objetivo abordar os aspectos mais gerais acerca do método de análise de performance de fundos de investimento em previdência complementar aberta no Brasil e as suas potencialidades como balizador de dados sociais e não apenas mercadológicos.

Nesse sentido, o papel do Estado e do mercado financeiro na questão previdenciária brasileira é motivo de extensos debates, nos quais apresentam-se divergentes teses e posicionamentos acerca da capacidade superavitária do modelo previdenciário brasileiro a longo prazo. Recentemente, no ano de 2019, foi promulgada a Emenda Constitucional io3, popularmente conhecida como a Reforma Previdenciária que, em síntese, é a resposta legislativa à sociedade em relação ao mencionado debate sobre a capacidade superavitária da previdência social.

A partir da condição supletiva, facultativa e complementar da previdência privada, emergiu a compreensão da inafastável relação entre a finalidade da administração dos recursos financeiros de terceiros e a finalidade social objetiva da previdência privada complementar aberta.

É notório que trata-se de um tema bastante complexo, no qual o presente artigo propõe-se a contribuir buscando compreender a capacidade de apreensão dos reflexos diretos e indiretos, tanto para o mercado financeiro quanto para o objetivo social a que se destina, a partir do método de análise da performance de fundos previdenciários privados.

Para tanto, a exposição da pesquisa dividiu-se em três grandes momentos. Inicialmente, uma abordagem sobre as estruturas do Regime Geral de Previdência Social (RGPS), do Sistema Financeiro Nacional (SFN) e as distinções entre as entidades de previdência privada de tipo fechado (EFPC) e aberto (EAPC).

Ato seguinte, foram retratados os aspectos teórico-práticos da análise de performance e as definições do Capital Asset Pricing Model (CAPM) a partir de índices financeiros, que são "medidas clássicas de performance de carteiras", como a razão de Sharpe e a razão de Treynor. Entretanto, essa abordagem não encerra a complexidade inerente à temática aqui abordada. Novos caminhos, novas discussões, como a utilização de outros benchmarks na comparação dos resultados, como Selic, dentre outros, foram trazidos para complementar o presente estudo. 
Por fim, o presente trabalho teve por intuito apresentar uma contribuição para uma literatura ainda escassa sobre o comportamento de aspectos relevantes da indústria de Previdência Complementar, principalmente, tendo em vista sua interrelação com variáveis macroeconômicas.

\section{BREVES CONSIDERAÇÕES SOBRE AS PARTICULARIDADES DO REGIME PREVIDENCIÁRIO PRIVADO NO BRASIL}

Este capítulo é apresentado a partir dos esforços em retomar conceitualmente as estruturas que compõem o regime previdenciário brasileiro. Obviamente, para tratarmos sobre as particularidades e potencialidades de um método de pesquisa estatístico voltado para a apreensão de dados referentes a investimentos financeiros em fundos previdenciários torna-se necessário esse movimento de apuração conceitual da própria estrutura de Previdência Social, neste caso brasileira.

O nascimento da previdência social remonta ao processo de conformação dos Estados modernos ocidentais, principalmente, no período do final do século XIX. Em decorrência das agruras impostas pelo modelo de Estado liberal, a noção de "proteção social" surge como um arcabouço de princípios e medidas a serem adotadas pelo Estado como forma de assegurar aos indivíduos direitos e garantias fundamentais para a sua sobrevivência.

A marcha evolutiva do sistema de "proteção social", se considerarmos desde a assistência prestada por "caridade", até o estágio em que se mostra como um direito subjetivo, garantido pelo Estado e pela sociedade a seus membros, apresenta-se como "o reflexo de três formas distintas de solução do problema: a da beneficência entre pessoas; a da assistência pública; e a da previdência social, que culminou no ideal de seguridade social” (CASTRO, LAZZARI, 2018).

Assim, tem que se ter em mente que a noção fundamental de que a Previdência Social se constitui como um direito subjetivo do indivíduo, direito este que é exercitado junto à sociedade ao qual pertence. O exercício dessa prerrogativa subjetiva impõe que a sociedade em conjunto participe efetivamente do regime de seguro social, por meio de aportes que garantam recursos financeiros suficientes à aplicação da política previdenciária. Entretanto, não há 
apenas um modelo único de se prover aos indivíduos a proteção social quanto a infortúnios que afetem sua capacidade de labor e subsistência.

Há que se considerar que os sistemas previdenciários separam-se, predominantemente, em relação ao custeio e conforme a fonte de arrecadação da receita necessária ao desempenho da política de proteção social. Em linhas gerais podem se dividir entre sistemas contributivos e não-contributivos.

A Previdência Social brasileira é composta por mais de um regime, dividindo-se em Regime Geral de Previdência Social (RGPS), Regimes de previdência de agentes públicos, Regime Dos Militares Das Forças Armadas e aquele que compõe o objeto do presente trabalho, que é o Regime Previdenciário Complementar.

Assim, a exploração da previdência pela iniciativa privada é tolerada pela ordem jurídica, porém apenas em caráter supletivo, ao contrário do que ocorre, por exemplo, no Chile, onde o regime previdenciário adotou a privatização da proteção previdenciária como fórmula básica.

A Lei Complementar n. I09/200I inicia preconizando os mesmos princípios estabelecidos no art. 202 da Constituição da República, quais sejam, o caráter meramente complementar do regime privado e a autonomia deste em relação à Previdência Social, assim como a facultatividade no ingresso e a necessidade de constituição de reservas que garantam a concessão dos benefícios (art. $\mathrm{I}^{\mathrm{o}}$ ). Nas modernas economias de mercado, o investimento não fica limitado aos recursos próprios dos empreendedores, podendo ser obtidos de terceiros.

O mercado financeiro, assim, é constituído pelo conjunto de instituições, práticas e normas que viabilizam as relações financeiras entre credores e devedores. Nesse mercado desenvolve-se a negociação de contratos de crédito, títulos de dívida e títulos de capital como ações - viabilizando a canalização de recursos de pequenos e grandes poupadores e de disponibilidades de uso corrente para o financiamento dos agentes dispostos a assumirem dívidas para aquisição de bens de consumo e de bens de capital. O financiamento tanto do consumo quanto do investimento amplia a demanda agregada e estimula o crescimento da renda e do emprego.

O sistema financeiro, como centralizador dos excedentes financeiros dos agentes superavitários, exerce o papel de converter os recursos que administra a curto, médio e longo 
prazos, inclusive disponibilidades de uso corrente, em créditos compatíveis com as necessidades dos tomadores (ESTRELA; ORSI, 2010).

Para isto, deve estar apto a avaliar a capacidade de pagamento dos devedores e a viabilidade dos projetos de investimentos que demandam financiamento, bem como estar disposto e habilitado a assumir os correspondentes riscos de crédito e de mercado.

A configuração desses instrumentos e os esforços adotados para reordenar o Sistema Financeiro Nacional foram impactados pelo cenário advindo da implantação do Plano Real, em julho de 1994. A estabilização de preços causou mudança de atitudes e de valores dos agentes econômicos e redefiniu os papéis dos órgãos reguladores e do próprio mercado financeiro.

Nas últimas décadas, o efeito de duas ordens de fatores localizadas nos planos externo e interno. No plano externo, destaca-se o impacto do processo de globalização econômica. No setor financeiro, a velocidade da integração dos mercados foi potencializada pelas redes de comunicação de dados entre os centros financeiros mundiais, e pela tendência de liberação do fluxo de capitais e flexibilização das regras de conversibilidade entre as moedas (ESTRELA; ORSI, 2010).

No plano interno destacam-se: a abertura da economia ao comércio exterior e as mudanças de política industrial visando a inserção mais competitiva dos produtos brasileiros nos mercados emergentes; o corte de subsídios a vários setores produtivos, com repercussões sobre a distribuição do crédito bancário e sua velocidade de retorno; a redistribuição de gastos do setor público, em especial com a adoção da política de estabilização fiscal e, posteriormente, com a aprovação da Lei de Responsabilidade Fiscal; e, por fim a iniciativa de reformas no ordenamento constitucional do País, notadamente na ordem econômica, na estrutura e nas funções do setor público, na organização administrativa do Estado e no sistema previdenciário.

Assim, o processo de reestruturação da economia brasileira alterou radicalmente o cenário em que atuavam as instituições financeiras (ESTRELA; ORSI, 2010). A abertura da economia, com o incremento das importações e exportações e o aumento do fluxo de capitais, além de exigir o desenvolvimento de produtos e serviços ágeis no mercado de câmbio, revelou o grau de ineficiência de alguns setores industriais domésticos, com baixa lucratividade e 
deseconomias que passaram a se refletir na incapacidade de recuperação de empréstimos ao setor privado.

No mesmo sentido, o corte de subsídios a alguns setores econômicos aumentou o grau de inadimplência para com o sistema bancário, que se elevou em relação à sua média histórica. Em outra dimensão, o esforço de equilíbrio das contas públicas diminuiu sensivelmente o ingresso de recursos na economia e, por consequência, a intermediação operada pelos agentes financeiros.

Dito isso, após a estabilização monetária e o arcabouço legal de tratamento da crise bancária, o Sistema Financeiro Nacional desenvolveu-se a partir de instituições como a própria Superintendência de Seguros Privados (Susep), uma Autarquia vinculada ao Ministério da Economia, responsável pelo controle e fiscalização do mercado de seguro, previdência privada aberta e capitalização (ESTRELA; ORSI, 20Io).

Dentre suas atribuições, destaca-se aquela de fiscalizar a constituição, organização, funcionamento e operação das Sociedades Seguradoras e de Capitalização, Entidades de Previdência Privada Aberta e Resseguradores. As funções do órgão regulador e do órgão fiscalizador são exercidas por intermédio do Conselho Nacional de Seguros Privados (CNSP). São regidas pelo Decreto-Lei 73, de 21 de novembro de 1966, e pela Lei Complementar 109, de 29 de maio de 200 .

As entidades de previdência complementar dos trabalhadores da iniciativa privada se dividem em fechadas e abertas, conforme se segue. a previdência complementar e a previdência social têm métodos operacionais diferentes, como exemplo, as crises da previdência social são resolvidas através de decretos, enquanto na previdência privada a solução depende da capacidade financeira das pessoas, uma é vinculada ao INSS, enquanto a outra subordinada a SUSEP (PÓVOAS, 1985).

A entidade fechada de previdência privada (EFPC) é aquela constituída sob a forma de fundação ou sociedade civil, sem fins lucrativos, e que é acessível exclusivamente a empregados de uma empresa ou grupo de empresas, aos servidores dos entes públicos da Administração, quando o tomador dos serviços será denominado patrocinador da entidade fechada, e aos associados ou membros de pessoas jurídicas de caráter profissional, classista ou setorial, quando estas serão denominadas "instituidores" da entidade. 
Não pode o próprio empregador explorar a atividade de previdência complementar; para estabelecer o plano previdenciário privado, deverá constituir entidade própria para este fim. Não se confunde, portanto, a personalidade jurídica da empresa patrocinadora ou instituidora (empregador) com a da entidade previdenciária complementar.

As entidades abertas de previdência complementar (EAPC) são aquelas que não se enquadram na hipótese anterior e são constituídas unicamente sob a forma de sociedade anônima, com fins lucrativos, que tem como objetivo principal, instituir planos que podem ter coberturas de morte, invalidez ou sobrevivência.

A Lei Complementar I09/or permitiu que as sociedades seguradoras que operem exclusivamente no ramo de seguros de pessoas sejam autorizadas a comercializar planos de previdência complementar.

Os planos das entidades abertas podem ser contraídos sob a forma individual ou coletiva. Os planos individuais são aqueles acessíveis a quaisquer pessoas físicas, enquanto os planos coletivos são aqueles destinados a pessoas físicas vinculadas, diretas ou indiretamente, a uma pessoa jurídica contratante, que pode participar do custeio do plano, conforme disposições constantes no contrato celebrado entre a pessoa jurídica contratante, e a entidade aberta.

As EAPC's, em termos econômicos, funcionam como formadoras de poupança, proporcionando renda futura aos segurados/cotistas, cujo valor dependerá do grau de eficiência dos gestores do plano de previdência complementar, na administração da carteira de investimentos. São instituições financeiras que exploram economicamente o ramo de infortúnios do trabalho, cujo objetivo é a instituição e operação de planos de benefícios de caráter previdenciário em forma de renda continuada ou pagamento único.

Em outra senda, importante mencionar as discussões recentes entre o universo político e acadêmico a respeito da introdução de um sistema de previdência privada de fato capaz de complementar o Regime Geral de Previdência Social (RGPS), tendo em vista o público que deseja uma renda de aposentadoria acima do teto.

O ganhador do Prêmio Novel de Economia (1997) Robert C. Merton, juntamente com Arun S. Muralidhar e Alexandre Vitorino, analisaram o caso brasileiro e publicaram um breve, mas notável artigo intitulado "SELFIES can help Brazil create a super supplementary 
pension" para sustentar que a previdência complementar ao RGPS no Brasil deveria ser SUPER: Simples, Universal, Portátil, Eficiente (baixo custo) e com a Regulamentação Robusta.

A partir desses valores, os autores sugerem a adoção de uma inovação financeira chamada SeLFIES: Standard-of-Living, Forward-started, Income-only Securities, que fosse apresentado como “opção de investimento padrão para um regime de capitalização moderno”. Os economistas perceberam que essa inovação financeira ajudaria o governo brasileiro a enfrentar dois desafios simultaneamente: melhorar a segurança da aposentadoria (incluindo até mesmo os mais analfabetos financeiramente e os do setor informal nos planos de aposentadoria) e impulsionar o financiamento de infraestrutura.

2. AS POTENCIALIDADES DA AVALIAÇÃO DA PERFORMANCE EM CARTEIRAS ABERTAS DE FUNDOS DE PREVIDÊNCIA COMPLEMENTAR

Os fundos previdenciários representam importante papel junto ao mercado de capitais, visto o grande volume financeiro captado. São considerados investidores institucionais e formadores de poupança de longo prazo. Desta forma, é muito importante que os recursos financeiros captados gerem retornos positivos de forma a garantir os benefícios futuros.

Como os recursos captados são reinvestidos em renda variável, certamente existe o risco, é muito importante que o administrador da carteira de investimento, tenha uma estratégia bem definida no processo, que seja eficiente a ponto de cumprir com todos os compromissos futuros.

Mediante processo de diversificação de carteira, esse risco pode ser reduzido, processo conhecido como risco não sistêmico. Essa estratégia tem como princípio evitar a concentração de recursos em determinadas ações, deixando também de selecionar ações que possuam perfil semelhante. Deve-se atentar aos indicadores básicos, quais sejam: a seleção de ativos e o market timing durante a execução na avaliação de performance de fundos de investimentos.

As variáveis frequentemente utilizadas em pesquisas empíricas são os dados referentes aos: i) Retornos mensais das carteiras dos fundos de investimento previdenciários ii) Retornos mensais da carteira de mercado; iii) Retornos mensais do ativo livre de risco. 
Como benchmarks referenciais de performance, são utilizados os índices de Certificado de Depósito Interbancário - CDI, referente ao ativo livre de risco, e o índice Bovespa IBOVESPA, referente ao ativo com risco, representando a carteira de mercado, dentre outros.

A "seleção de ativos" apresenta um problema para o desenvolvimento da metodologia de avaliação de desempenho, onde o foco são peculiaridades da seleção de ativos do fundo em análise. Já no segundo item, o "market timing”, o problema de avaliação de desempenho se resume na habilidade do gestor em conseguir performance superior ao índice de mercado.

Pode-se dizer que as duas abordagens mais utilizadas para avaliação de performance de fundos de investimentos são:

- A comparação da performance passada de fundos com a de seus benchmarks, ou, a de fundos de investimento similares, entendidos como aqueles que se encontram dentro de uma mesma classe;

- A determinação da responsabilidade sobre a performance passada, se ela ocorreu devido às habilidades do gestor ou, se foi simplesmente sorte.

A avaliação de desempenho de fundos de investimentos deve sempre considerar retorno e risco passados simultaneamente. É recomendado analisar a questão, levando em conta os retornos ajustados aos riscos do passado e não se limitar apenas à análise de figuras (DUARTE, 2005).

O pesquisador Jacob Bikker, a partir de dados exclusivos para fundos de pensão holandeses entre 1992-2009, juntamente com Jan de Dreu, examinaram como o impacto dos determinantes custos administrativos e de investimento por participante parecem variar amplamente entre os fundos de pensão. Segundo os autores, esses custos são importantes porque reduzem a taxa de retorno dos investimentos dos fundos de pensão e, consequentemente, aumentam o custo da segurança da aposentadoria. Nesse sentido, conseguiram demonstrar que as economias de escala dominam a forte dispersão dos custos administrativos e de investimento nos fundos de pensão. Os fundos de pensão em todo o setor são significativamente mais eficientes do que os fundos de empresas e outros fundos (BIKKER; DREAU. 2007).

Existem, também, algumas medidas de desempenho interessantes para avaliação de fundos de investimentos, que consideram retornos ajustados a riscos. Elas podem ser 
chamadas também de razões de eficiência e destacam-se duas delas, sendo: a "razão de Sharpe"; a "razão de Treynor".

Esta metodologia pode ser classificada como descritiva e tem como intenção avaliar o comportamento da performance dos investimentos previdenciários em relação à movimentação do benchmark de mercado, usualmente CDI ou o Ibovespa. Assim, este método promove uma análise qualitativa da performance dos planos previdenciários através do uso de índices financeiros de CAPM em "medidas clássicas de performance de carteiras" (Sharpe e Treynor) que, costumeiramente, são utilizados como balizadores dessa performance.

O Capital Asset Princing Model (CAPM), representa uma das metodologias empregadas por administradores na medição de riscos de mercado. O CAPM é um modelo estatístico usado por administradores de fundos de investimento na medição de riscos, ele propõe que o retorno esperado da carteira seja igual à taxa de um ativo livre de risco mais uma remuneração atrelada ao risco assumido pelo investidor.

Para que se tenha uma adequada utilização desse modelo, deve-se ter em consideração alguns pressupostos intrínsecos, tais como expectativas homogêneas, quanto ao risco e retorno por parte dos investidores; ausência de custos nos investimentos financeiros; ausência de custos sobre os ganhos; os preços dos títulos, que estão embutidas todas as informações disponíveis ao mercado; tratamento universal das informações, além das características inerentes aos perfis de investidores, que optam por carteiras que apresentem menor risco para o mesmo retorno; que fazem carteiras que apresentem menor risco para o mesmo retorno e aqueles que avaliam as carteiras de investimento da mesma forma.

Todos esses pressupostos refletem a lógica do modelo CAPM e do mercado eficiente, levando em consideração que todos os investidores sempre irão aplicar seus recursos financeiros em ativos com risco e livre de risco. Ressaltando, o modelo CAPM qualifica o mercado como provedor eficiente dos preços de ativos financeiros e, é o que se chama de mercado eficiente.

Ao considerar uma carteira de investimentos define-se que o objetivo principal do modelo CAPM, mediante hipóteses de equilíbrio conforme descrito acima, é eliminar o risco dos ativos individuais, atribuindo assim a toda carteira, apenas o risco sistemático, mediante estratégia de diversificação. 
Mesmo mediante estratégia de diversificação, não se é capaz de eliminar o risco sistemático dos ativos estando todas as empresas sujeitas a esse tipo de risco. Conforme anteriormente mencionado, seguir-se-á com a conceituação teórico-prática das "medidas clássicas de performance de carteiras” - a razão de Sharpe e a razão de Treynor.

Para efeito de comparação entre a razão de Sharpe e a razão de Treynor, usualmente, quando aplicadas ao mesmo conjunto de fundos de investimentos, apresentam resultados bastante similares. Considera-se dois benchmarks (CDI e o Ibovespa) cuja natureza do risco situam-se em contraposição, uma vez que o CDI é um ativo livre de risco, e o IBOVESPA um indicador cujo ativo está umbilicalmente dependente ao risco de mercado. Portanto, torna imprescindível calcular os retornos esperados dos mesmos.

A razão de Sharpe tornou-se bastante popular no mercado financeiro brasileiro, principalmente, tendo em consideração as duas últimas décadas. Atualmente, a razão de Sharpe é usada especialmente na ordenação do desempenho de fundos de investimento. Logo, pode ser compreendida a partir da equação dada como: prêmio de risco/risco total.

Detalhando melhor tal equação, pode-se dizer que a parte superior da mesma representa a diferença entre o retorno esperado da carteira de mercado e do ativo livre de risco. Já o risco total é medido pelo desvio padrão do retorno do fundo (DUARTE, 2005). Dessa forma, a doutrina confirma duas formas de se maximizar a equação em referência, de maneira que: i) para um dado nível de risco total, o prêmio de risco é máximo, ou; ii) para um dado prêmio de risco, o risco total é mínimo.

Dessarte, quanto maior a razão de Sharpe, do fundo de investimento, melhor deve ser considerando seu desempenho, referente ao período coberto.

No entanto, importante ressaltar que pode ocorrer uma limitação no uso prático da razão de Sharpe, que está relacionada à possibilidade de se obter estimativas negativas a partir dos dados processados. Quando isto ocorrer é necessário observar de forma criteriosa o retorno esperado e o risco total do fundo de investimento para que seja feita a mensuração correta dos dados. 
A razão de Treynor, por sua vez, representa o prêmio ganho por unidade de risco assumido, sendo o risco da carteira de investimentos, assumido pelo coeficiente beta ${ }^{2}$. A equação que representa de forma sintética o método analítico para se calcular o índice de Treynor é trazida pelo prêmio de risco/prêmio sistemático.

Nesse caso, considera-se o risco sistemático, como o beta da carteira, em relação a um índice escolhido como benchmark. Para a utilização da razão de Treynor, requer uma estimação cuidadosa dos betas dos fundos de investimentos e ao acesso à base de dados confiável na estimação desse beta, que geralmente possui grande dificuldade em estimação.

O índice de Treynor, de uma forma geral, representa o prêmio de risco ganho, mediante o risco assumido, onde o risco da carteira é medido pelo beta (DUARTE, 2005).

Para a efetiva realização da análise da performance da carteira de cada plano previdenciário é necessário estruturar os dados de acordo com os modelos propostos de maneira a identificar na variável excesso de retorno.

A partir do método de precificação de ativos CAPM, os índices encontrados em Sharpe e Treynor são utilizados como determinantes na avaliação da performance dos fundos de investimento. Nesse contexto, para que a carteira referente ao fundo de investimento previdenciário tenha bom desempenho torna-se necessário que os valores dos respectivos índices sejam positivos.

Quanto aos resultados do índice de Sharpe, conforme já mencionado anteriormente, certamente à medida do desvio-padrão fará muita diferença no seu cálculo, visto que esse índice atribui ao desvio-padrão significado análogo ao de risco total da carteira, portanto, quanto maior o desvio-padrão maior o risco. Sabe-se que é calculado mediante retorno médio da carteira, menos o retorno do ativo livre de risco, dividido pelo desvio-padrão da carteira.

Quanto aos resultados do índice de Treynor, considera-se que a carteira de ativos da entidade financeira tenha passado pelo processo de diversificação, ou seja, a carteira estará sujeita a um único tipo de risco, denominado risco sistêmico medido pelo coeficiente beta.

\footnotetext{
${ }^{2}$ Em síntese, a descrição do coeficiente beta é trazida como sendo ele o responsável por medir a sensibilidade de um título aos movimentos de mercado (ROSS, 2002). O risco pode ser definido pela variabilidade do retorno ao índice de mercado escolhido, ou seja, o risco de uma ação individual é medido por sua contribuição a essa variabilidade. Em síntese, ambos os autores dão a mesma interpretação ao termo (DUARTE, 2005).
} 
Assim, deve-se interpretar o coeficiente de regressão de "beta", que é responsável por mensurar a exposição do investidor ao risco sistemático, ou seja, o risco de mercado, que precisa ser mensurado e não é eliminado pela diversificação. Sendo assim, pode-se dizer que quanto maior a volatilidade, maior o risco; betas menores, riscos menores, betas maiores, riscos maiores.

Entretanto, essa abordagem não encerra a complexidade inerente à temática aqui abordada. Importante ressaltar que podem ser criados novos caminhos, novas discussões, como exemplo, a utilização de outros benchmarks na comparação dos resultados, como Poupança, Selic, CDB, entre outros.

Nesse sentido, imperioso retomar os resultados do trabalho de Luiz Carpizo e Marcio Garcia intitulado como "Regulação ineficaz para forçar alongamento: $\mathrm{O}$ caso da Previdência Complementar Aberta no Brasil”, publicado em 2019, na Revista Brasileira de Finanças (Online).

Os autores destacam como motivação a lenta queda da taxa de juros observada no Brasil nas últimas décadas, o que de fato, passa a representar uma curiosidade de como vão se portar as Entidades Abertas de Previdência Complementar, principalmente, no que tange à composição de suas carteiras.

Tais entidades, conforme pode se observar, aproveitavam-se de um histórico de altas taxas de juros no país como forma da manutenção de grande parte de seus recursos alocados em instrumentos indexados à taxa Selic. Dessa forma, pode se dizer que, foram capazes de garantir uma rentabilidade aceitável de maneira segura em face de recessões econômicas.

Outro ponto em destaque, diz respeito a necessidade de se compreender a sensibilidade dos diferentes componentes da carteira de investimento desse setor que encontra-se interrelacionada a instrumentos que compõem a base da política monetária do país. Portanto, isso se torna preponderante para avaliar a eficiência da gestão, principalmente, de longo prazo realizada pelas instituições e os impactos de um possível cenário de manutenção das taxas de juros em níveis baixos em relação ao nível histórico.

Carpizo e Garcia acenam ainda para a compreensão de outro aspecto inexorável: o nível de impacto que essas entidades efetivamente exercem para um maior alongamento e desindexação da dívida pública federal. Aduzem, por se tratarem de entidades cujo passivo é 
mais alongado no tempo, espera-se justamente que estejam mais propensas à tomada de risco de longo prazo e menos focadas em retornos e ativos de curto prazo. Tal contribuição se faz especialmente atraente no atual cenário de queda gradual de juros com inflação controlada.

Há que se destacar ainda o mérito dos autores em questão que se dedicaram a um estudo detalhado com dados de alocação de portfólio de grandes entidades para a avaliação o impacto da taxa de juros sobre decisões de gestão de carteira, tudo isso, aliado a uma análise do efeito causal da regulação sobre a tomada adicional de risco.

O resultado de suas pesquisas os conduziu a uma compreensão de que a "gestão realizada nos principais fundos das EAPC's é consideravelmente sensível à taxa de juros de curto prazo, com choques de um desvio de padrão na Selic responsáveis por um aumento da indexação da carteira e redução da exposição de risco a títulos de longo prazo”.

Em um cenário de queda gradual da taxa de juros, tal sensibilidade pode vir a ser positiva, na medida em que contribuiria para o alongamento da dívida pública e desindexação em relação a taxa de juros do mercado de títulos públicos federais.

Para decisões de política monetária, portanto, o importante será transmitir credibilidade na capacidade de sustentar uma taxa de juros consistentemente mais baixa, o que passa diretamente pela eficiência do Banco Central em manter a inflação controlada, enquanto decisões de política fiscal devem contribuir para a redução do risco sistêmico no país.

No entanto, conforme o artigo em questão, destaca-se que o desejo dos gestores de fundos de EAPC's acabam por replicar um benchmark passivo ao projetarem com os índices Selic/CDI. Essa postura apresenta-se de maneira problemática na medida em que as taxas de administração cobradas por esses fundos estão consideravelmente acima da média do mercado (CARPIZO; GARCIA, 2019). Os investidores, portanto, estariam em uma situação melhor se migrassem seus investimentos para fundos referenciados com menores taxas.

Dito isso, os fundos previdenciários que são administrados percorrendo resultados longo prazo a podem enfrentar problemas durante períodos de pior rentabilidade e maior variabilidade da cota, dado que os clientes podem a qualquer momento resgatar seus investimentos e transferi-los para outros fundos do mesmo setor, os quais apresentem menores índices de confirmação dos riscos, consequentemente, menor volatilidade de seus 
recursos. No entanto, insta mencionar que os custos administrativos por participante parecem variar amplamente entre os fundos de pensão em diferentes países (BIKKER, 20II).

\section{CONSIDERAÇÕES FINAIS}

O presente artigo teve seu foco direcionado ao mercado da iniciativa privada representadas pelas EAPC's, entre elas estão os bancos e as seguradoras. Estes considerados grandes entidades financeiras, com características de formadoras de poupança de longo prazo.

Ao longo da exposição foram apontados a responsabilidade pública estatal em torno da Previdência Social: o sistema financeiro nacional, onde de forma breve procurou associar uma constante deste trabalho, que está muito relacionada ao tema, o risco.

Posteriormente, discutiu-se a previdência social, seguida da previdência complementar, esses dois tópicos serviram como pontos preponderantes na visualização de gargalos sociais presentes na esfera pública e a conscientização da grande necessidade de se pensar em previdência complementar como forma de complementação de renda aos contribuintes da previdência social no futuro.

Diante das inúmeras possibilidades de investimento no universo financeiro, a preocupação em avaliar a performance de carteira de fundos previdenciários brasileiros ganha extremo relevo na medida em que o sistema previdenciário passou por uma intensa reforma legislativa, sem de fato retirar a responsabilidade do Estado-previdência, mas atribuindo ao mercado uma projeção significativa em torno da necessidade de se pensar em previdência complementar como forma de complementação de renda aos contribuintes da previdência social.

Segundo a maioria dos corretores, a principal motivação dos participantes para as portabilidades é a intenção de obter mais ganhos/ melhor rentabilidade, seguida pela busca de planos previdenciários com taxas mais baixas. A primeira motivação para os resgates, segundo a maioria dos corretores, é a necessidade do recurso; e a última motivação a descrença no produto (SILVA, 20I6).

Portanto, é razoável dizer que a performance de fundos de investimento previdenciários pode ser considerada uma ferramenta importante na percepção sobre a administração do fundo ou plano de previdência complementar. 
A avaliação do comportamento de carteiras de fundos previdenciários brasileiros é um assunto capaz de gerar muita discussão, pois são diversas as maneiras que os administradores de carteiras de investimento usam como forma alternativa para trabalhar os recursos financeiros de terceiros no mercado.

No entanto, em cada uma das alternativas, o objetivo final é o mesmo, a superação da carteira de mercado, com alcance de maiores rentabilidades, se possível com menor risco.

Pode-se dizer que, conforme abordado anteriormente, amplia-se a possibilidade de inserção de investimentos em fundos de pensão de tipo aberta no planejamento patrimonial dos cidadãos, principalmente, a partir da EC I03. Assim, pode se tornar uma solução frente a expectativa de insustentabilidade da previdência social.

Diante da relevância temática, surgiu o questionamento que se refere às potencialidades da análise de performance de fundos de previdência complementar aberta. Nesta parte, foram abordadas algumas técnicas estatísticas e financeiras de avaliação de performance de fundos previdenciários estudados, na qual foram trazidos os aspectos teóricopráticos do método de precificação de ativos - CAPM, e os índices utilizados como balizadores de performance dos fundos previdenciários, sendo eles, a razão de Sharpe e a razão de Treynor.

Como revisão, reescreve-se o problema proposto para essa pesquisa: Analisar apenas a performance passada dos fundos de investimento previdenciários é suficiente para se ter percepção consistente sobre os reflexos diretos e indiretos da administração do fundo ou plano de previdência complementar?

Como resposta ao problema proposto acima, o método de CAPM a partir da razão de Sharpe e, também, de Treynor podem ser balizadores eficientes para o controle e gestão dos dados de investimentos/riscos para a administração dos fundos de investimento previdenciários.

Portanto, é razoável dizer que a análise performance passada de fundos de investimento previdenciários pode ser considerada uma ferramenta importante na percepção sobre a administração do fundo ou plano de previdência complementar.

Baseado na constatação do parágrafo acima se percebe que os contribuintes desses fundos previdenciários têm o direito de no mínimo contestar a real capacidade desses gestores em gerar retornos significativos aos fundos previdenciários. 
No entanto, diante da modificação legislativa em torno da fiscalização e controle dessa atividade financeira, viu-se insuficiente para a compreensão da postura atualmente adotada pelos gestores das EAPC's, que diante da queda da taxa de juros nos últimos anos, passaram a utilizar a taxa Selic como índice de medição do risco, sem o acompanhamento da diminuição da taxa de administração referente, o que por sua vez, acaba por aumentar o risco sistêmico da economia.

\section{REFERÊNCIAS BIBLIOGRÁFICAS}

BERZOINE, Ricardo...[et al].; A Previdência Social no Brasil. - I. ed. - São Paulo: Fundação Perseu Abramo, 2003. Parte 3, p. 99-II9.

CARPIZO, Luiz Guilherme; GARCIA, Márcio Gomes Pinto. Regulação ineficaz para forçar alongamento: $O$ caso da Previdência Complementar Aberta no Brasil. Revista Brasileira de Finanças (Online), Rio de Janeiro, Vol. 17, No. 4, dez. 2019, pp. 33-55ISSN 1679-0731, ISSN online $1984-5146$.

BIKKER, J. A. (2017). Is there an optimal pension fund size? A scale-economy analysis of administrative costs. Journal of risk and insurance, Malvern, USA, 8(2), 739-769. https://doi.org/ıo.IIII/jori.12103

BIKKER, J. A., \& De Dreu, J. (2009). Operating costs of pension funds. Journal of pension economics and finance, 8(I), 63-89. https://doi.org/ro.1017/Si474747207002995

BIKKER, J. A., Steenbeek, O., \& Torracchi, F. (2012). The impact of scale, complexity, and service quality on the administrative costs of pension funds: a cross-country comparison. Journal of risk and insurance, 79(2), 477-514.

CASTRO, Carlos Alberto Pereira; LAZZARI, João Batista. Manual de direito previdenciário - 21. ed. - Rio de Janeiro: Forense, 2018.

DUARTE, Antônio M. J.; Gestão de Riscos para Fundos de Investimentos. São Paulo: Prentice Hall, 2005. Cap. V, p. 51-6I, Cap. VII-VIII, p. 77-II2.

ESTRELA, Márcio Antônio; ORSI, Ricardo Vieira. Moeda, Sistema Financeiro E Banco Central: Uma Abordagem Prática E Teórica Sobre O Funcionamento De Uma Autoridade Monetária No Mundo E No Brasil. atualização da edição de 2006. redigido com informações disponíveis até 2010.

MARQUES, Rosa M....[et al].; A Previdência Social no Brasil. - I. ed. - São Paulo: Fundação Perseu Abramo, 2003. Parte I, p. 17-30. 
MORAIS, Adriano Giacomini. Estatística para economistas: comentários e exercícios resolvidos para ANPEC. I. ed. - São Paulo: Central de Ensino para Graduados, 2009. Cap. X, p. 170-175.

MERTON, Robert; MURALIDHAR, Arun; VITORINO, Alexandre. Selfies Can Help Brazil Create A Super Supplementary Pension. Rev. Bras. Prev., Curitiba, Paraná. v.iI n.I, p.o4-II, Janeiro-Junho. 2020.

PERES, Marcos A. S.; Previdência Complementar. - 6. ed. - Rio de Janeiro: FUNDAÇÃO ESCOLA NACIONAL DE SEGUROS - FUNENSEG, 2008. Cap. II-III, p. 15-5I.

PIMENTEL, José...[et al].; A Previdência Social no Brasil. - ı. ed. - São Paulo: Fundação Perseu Abramo, 2003. Parte 2, p. 5I-68.

PÓVOAS, Manuel S. Soares; Previdência privada: filosofia, fundamentos técnicos e conceituação jurídica. I. ed. - Rio de Janeiro; Funenseg, 1985. Cap. III, p. 59-91.

ROSS, Shepehen A.; Administração Financeira. - 2. ed. - São Paulo: Atlas, 2002. Cap. IX-X, p. I89-239.

SILVA, Alex Rodrigues da. Análise Da Dinâmica Do Mercado De Previdência Complementar Aberta - 2003 a 2014. Dissertação de Mestrado - Curso de Mestrado Profissional em Administração da Fundação Pedro Leopoldo. Pedro Leopoldo-MG. 2016, ı04p.

TEIXEIRA, Rudolph; RODRIGUES, Adriano. Economies of scale in Brazilian closed supplementary pension entities: is there an optimal size? Revista Contemporânea de Contabilidade, Florianópolis, v. I8, n. 46, p. 97-II2, jan./mar., 202I. 